\title{
The Lamp of Reason and the Mirror of Nature ${ }^{1}$
}

\author{
Preston Stovall \\ Forthcoming in an anthology edited by Randall Auxier, published by Lexington Books.
}

When Rama spoke the secret mantras, the lords of the astras appeared before him. They were neither of this world nor yet in the next: they stood between the realms, their bodies of pristine light.... They said to Rama, "Now we are your slaves; we will do your bidding, whenever you want." Rama said to them, "Dwell in my mind, until I have need of you."

The Ramayana

At the close of Philosophy and the Mirror of Nature (PMN) Richard Rorty lays out the contrast between what he calls 'systematic' and 'edifying' philosophical methodologies. Whereas the systematic philosopher aims to speak for the ages, the edifying philosopher addresses herself to the issues of her day, often by way of shattering conventional idols (PMN, 368-70). The book itself, as a critique of the mirroring metaphor that Rorty finds in modern and contemporary epistemology, is meant to be an exercise in edification. Rorty encourages us to give up the effort to discern, once and for all, how the mind relates to the world, and instead take up the task of constructing new modes of understanding ourselves and the world. He likens the edifying philosopher to the poet, for whom "there is something new under the sun, something which is not an accurate representation of what was already there, something which (at least for the moment) cannot be explained and can barely be understood" (PMN, 370). But there are

\footnotetext{
${ }^{1}$ I would like to thank the participants of the Conference on American and European Values IX, the faculty and students of the philosophy department of Indiana University of Pennsylvania, and Robert Brandom and John McDowell for discussion concerning the material presented in this paper.
} 
many routes through philosophical systematics, and one might question the bifurcation Rorty proposes. Might there not be a mode of systematic philosophical inquiry, understood as the effort to construct a theory of knowledge that was meant to be passed on to future generations, and yet which was edifying in the sense that it called for iconoclasm and the cultivation of new modes of discourse? Why suppose that those who "build for eternity" cannot also be those who "destroy for the sake of their own generation" (PMN, 369)?

The aim of this paper is to defend a conception of philosophy as both systematic and edifying in the relevant senses. In Part 1 I lay the groundwork for the view by responding to Rorty's argument that Wilfrid Sellars' account of picturing involves an illicit 'mind as mirror of the world' metaphor. I argue that Sellars' theory of picturing was instead meant to function inside a given language as a warrant for assessing truth-evaluable claims across radically different conceptual schemes. Part 2 returns to the contrast between systematic and edifying philosophical projects. By sketching some of the philosophical anthropology that motivates Sellars' understanding of picturing as a dimension of epistemic warrant, and suggesting that this anthropology is descended from a philosophical endeavor with roots in 19th century European and American philosophy, I argue that the view we are left with is one that urges our taking up a project left to us by earlier generations, but with the understanding that in doing so we are in the business of creating new ways of thinking about ourselves as part of the natural world. In this way I underwrite the contention, broached at the end of the last paragraph, that the close of Philosophy and the Mirror of Nature does not exhaust the space of options for conceiving the relation between systematic and edifying philosophy. I finish with a suggestion as to what it might mean to "go beyond" Richard Rorty. 


\section{Part 1: Picturing and the Mirror of Nature}

Rorty construes commitment to the mirror motif as commitment to the supposition that there is a relation between mind and world such that, if we could specify it, we could once-and-for-all establish that the way thought (or a language) represents the world was right. At page 293 of PMN Rorty characterizes this as the demand "for some transcendental standpoint outside our present set of representations from which we can inspect the relations between those representations and their object," and writes:

This is the demand which Berkeley told us we could not meet, which Kant met only by calling the world "appearance," and which the image of the Mirror of Nature makes us think we ought to be able to meet.

While Rorty praises Sellars' holistic understanding of meaning as proof against the suggestion that we could ever secure an eternal epistemic metalanguage, a tool for critiquing all discourse (PMN, 170-1), Sellarsian picturing is nevertheless, Rorty believes, an effort in the direction of mirroring (PMN, 295-9). In the next few pages I show that this characterization of Sellarsian picturing is not supported by a close reading of Sellars. First, some background.

Sellars conceived of picturing as a relation between linguistic episodes (or mental events more generally) and the environment that could, in principle, be specified by an isomorphic function between these two domains. If we were in possession of this function, we could (in cases when the picturing was accurate) in principle read information about the mind off of the world, and information about the world off of the mind. E.g., if the picture were accurate an utterance of the sentence 'the cup is on the table' will tell you that the cup is on the table. Two things are important to note here. First, until very late in his career Sellars restricted his consideration of mental events to linguistic utterances, often to the point of making it seem as 
though, on his view, anything that could not speak could not think. ${ }^{2}$ Whether or not this was Sellars' considered view, early in his career he concluded that linguistic categories offered a tolerably precise set of resources for constructing, by analogy, a theory of mental events more generally (see, e.g., §50 of Empiricism and the Philosophy of Mind; at the end of that section Sellars refers us to two papers from the early 50's). Second, it is evident that Sellars nevertheless thought of central nervous system episodes as the proper domain for the mental side of picturing's isomorphism (cf. the last section of the 1960 paper "Being and Being Known," a paper devoted to an extended discussion of picturing). I will follow Sellars and begin by thinking of mental events on analogy with linguistic events. But in part 2 I will suggest that the move from the manifest to the scientific image of the person in the world requires a more careful attention to underlying CNS processes.

It is crucial for Sellars that both 1) linguistic episodes are only intelligible, qua linguistic, when they are understood within a normative categorical frame employing concepts like commitment and warrant, and 2) linguistic episodes qua objects of empirical inquiry are capable of being described without the use of any such vocabulary. It is this second mode of understanding that is at work in talk of picturing. Rorty charges that this bit of theorizing "is not useful in explaining how language is learned or understood" (PMN, 295), and after discussing Sellars' (and his student Jay Rosenberg's) treatment of picturing Rorty writes (PMN, 297) that on this view:

...mentality and intentionality are irrelevant to understanding how the Mirror mirrors.

The crucial sort of representing - the one which helps us say how and why we are

\footnotetext{
2 Papers like "Mental Events" and "The Lever of Archimedes," both published in 1981, show that by this point in his career Sellars has a more magnanimous conception of the mental. I am inclined to think this conception was there from the beginning, with the early supposition that language-use is the sine qua non of thought adopted as a means of clearing a conceptual space within which to work up a coherent view, afterwards to be extended (along with a commentary) in the direction of nonlinguistic thought and the rudiments of agency.
} 
superior to our ancestors - is one which takes place not relative to a scheme of conventions, not relative to intentions...

In response to his reading of Sellars, Rorty deploys an argument given by Putnam: any language in which such a relation was characterized would be itself susceptible to whatever concerns mirroring was supposed to solve; the problem of mirroring iterates up the metalinguistic hierarchy. To specify the relations by which some language $\mathrm{L}_{1}$ correctly mirrors the world one must use a (possibly identical) language $\mathrm{L}_{2}$; but then the relations between $\mathrm{L}_{2}$ and the world, which relations are invoked in underwriting the contention that $\mathrm{L}_{1}$ is correctly mirroring the world, will be just as subject to skepticism over mirroring as were the relations between $\mathrm{L}_{1}$ and the world. From PMN page 298:

Putnam is saying that the attempt to get a set of nonintentional relationships (such as those offered by a causal theory of reference or by a Sellarsian notion of "more adequate picturing") is always vitiated by the fact that those relationships are simply further parts of the theory of the world of the present day.

First, while it is true that Sellars' theory of picturing is supposed to be a characterization of thought/world relations that does not make use of mental-state or normative vocabulary, it does not follow "mentality and intentionality are irrelevant to understanding how the Mirror mirrors." Rather, the social practices involved in grooming a person's linguistic dispositions, and so establishing whatever determinate picturing relations there happen to be between her and the world, are practices shot-through with intentionality and normativity, as Sellars recognized and spent much of his career considering. In any community in which people communicate via conventional signs, the pictures the speakers of that language deploy picture as they do only because of the practices of education that govern linguistic education. And those practices are as 
'fraught with ought,' to adopt Sellars' phrase, as Rorty could want. Part 2 of the current paper discusses the philosophical anthropology lying behind Sellarsian picturing in more detail. For now the point can be put with an analogy of the sort Sellars was fond of. The fact that there might be an account of a game of chess that exclusively employed descriptive vocabulary about the positions of variously shaped pieces of wood at different times does not entail that this vocabulary could, even in principle, suffice as an explanation of what it is to play a game of chess, or of how there came to be chess players. Still less would it suffice as a vocabulary for the game's instructions. But it does not follow that such a descriptive vocabulary would be useless in explaining a chess game or teaching someone how to play.

The meat of Rorty's critique lies with his use of Putnam, and so to assess that critique we need to determine whether Sellars' account of picturing is subject to refutation via Putnam's observation that every effort to capture such a relation will always proceed from within a given discourse. Rorty's point of contact for his reading of Sellars on this issue is a passage in the middle of Science and Metaphysics. In that passage Sellars writes (142; this passage is quoted by Rorty at PMN 296-7):

...although the concepts of 'ideal truth' and 'what really exists' are defined in terms of a Peircean conceptual structure they do not require that there ever be a Peirceish community. Peirce himself fell into difficulty because, by not taking into account the dimension of 'picturing,' he had no Archimedean point outside the series of actual and possible beliefs in terms of which to define the ideal or limit to which members of this series might approximate.

On the face of it this may look as though Sellars is suggesting that with picturing we reach an "Archimedean point outside the series of actual and possible beliefs." But on closer examination 
Sellars should be understood as rejecting the need an Archimedean point, not endorsing picturing as a means to uncover it.

In the chapter of Science and Metaphysics from which this passage is taken (chapter 5), Sellars is developing an alternative to Peirce's view of truth as "that which is fated to be ultimately agreed to by all who investigate" $(1878,139)$. Sellars thinks that because Peirce left it inconceivable how the language at the end of inquiry might relate to ours, and because he defined truth in terms of the end of inquiry, he left the notion of truth in our language inconceivable. In contrast to this millennial understanding of truth, Sellars wants to provide a detailed account showing that we can, even now, understand ourselves to be (in principle capable of) uttering truths that would be recognized as such by those who come after us. Toward this end, Sellars set for himself the task of explaining how truth could be assessed across radical changes in conceptual schemes, and picturing is supposed to help here (notice that this is not Davidson's sense of 'conceptual scheme' - for the point is precisely to permit translation between schemes). Picturing is deployed as a mechanism for determining whether a claim made in one conceptual scheme is true in terms of another scheme, even though those schemes embody different views of the world. When the two utterances fall into a common 'propositional family,' as determined by the later community's assessment of the ways the utterances picture the world, and when the later utterance is recognized as a truth in the later language, then the earlier utterance will be recognized as true by the speakers of that later language as well (at page 132 Sellars is clear that the assessment of truth is always relative to the language in which the propositional families and their members are individuated). With this account we are supposed to see that an ancient Egyptian utterance (in their language) of "the sun rises in the east" was true 
by our lights when uttered by them, even though the ancient Egyptians had a very different view of the sun and its activities. ${ }^{3}$

Though every case of demarcating the propositional families of different languages will proceed from within a given language, so that we are always on the hook that we might have made some mistake that a future generation will need to correct, it is nevertheless coherent that we are, even now, mostly right about lots of things. While for Peirce truth is not in hand until we are at the end of inquiry, Sellarsian truth offers the prospect that we are even now uttering truths that those at the (hypothetical) end of inquiry will recognize as truths. In criticizing Peirce as he does Sellars is not declaring (as Rorty seems to suppose) that with a proper theory of picturing we would finally reach the Archimedean point from which to once-and-for-all assess the representational bona fides of a language. He is instead declaring that with picturing we no longer need that point in order to underwrite the possibility that we are speaking end-of-inquiry truths right now. Because of this, Putnam's argument (that any language purporting to grasp hold of the mind/world connection will itself be subject to whatever suspicion raised the initial worry about whether a language was successfully representing the world) does not stand as a refutation of Sellarsian picturing. ${ }^{4}$ For it was never Sellars' contention that the language in

\footnotetext{
${ }^{3}$ Actually, this issue is more complex, and Sellars does not tell us how to specify propositional family resemblances. It may be that in the details we would decide that the ancient Egyptian cosmos is too unlike our own for their utterance and ours to fall into the same family. For we might think that the worldview encoded in a claim that would be translated into our language literally as, say, 'Ra is reborn as a scarab from the waters of the underworld' was too dissimilar to our own to constitute anything like a picture of the sun rising in the east. I suspect that a consideration of the place of the two utterances in their respective subjunctive spaces might go some way toward enabling us to see them as sharing a common picture, and perhaps an attention to the subjunctive profile of an ordinary descriptive claim could be used as a mechanism for classifying such claims according to their propositional families.

${ }^{4}$ Rorty could at this point respond that the very notion of an "end of inquiry" ought to be rejected, so that insofar as Sellars thinks such a notion intelligible his theory of truth ought to be dismissed on that basis. This move remains open to Rorty, of course; but my point here has been to show that Sellars' account of picturing does not fall victim to the mirroring critique that, as a matter of fact, Rorty deploys against him (and at any rate Sellars does not need an 'end of inquiry' to get his account of picturing off the ground; all that is needed is a recognition of radically different
} 
which the picturing relation is specified is supposed to itself be somehow 'outside' a community's conceptual scheme or the revisions of those who come later. This leaves open just what the role of picturing is in a Sellarsian theory of knowledge. In the remainder of part 1 will argue that one role played by picturing is as a warrant for recognizing someone as a perceptual knower. As I think the view articulated here is basically Sellars' view, I will not belabor the exegetical details. ${ }^{5}$

At the end of section 36 in Empiricism and the Philosophy of Mind Sellars writes that "in characterizing an episode or a state as that of knowing, we are not giving an empirical description of that episode or state; we are placing it in the logical space of reasons, of justifying and being able to justify what one says." ${ }^{16}$ On this view of knowledge ascription, to say that someone knows something is not to be understood, in the first instance, as a description of them. Rather, knowledge ascription is to be understood as conferring a sort of social recognition on someone. And most forms of social recognition are, in many of their particulars, distinct from factual considerations about the individuals that are accorded those recognitions. That an individual in our society is able to enter into contractual arrangements upon turning 18 years of age, thereafter

conceptual schemes and the possibility of assessing truth across those schemes in virtue of shared picturing relations - talk of an 'end of inquiry' sets up an extreme case of this assessment, and provides a nice contrast with Peirce's view, but it is not essential to Sellars' account). My thanks to Robert Brandom for raising the possibility of this Rortyean rejoinder.

${ }^{5}$ I avoid textual exegesis for reasons of economy as well. Sellars' discussion of picturing is one of the most difficult dimensions of his philosophy, and it makes a showing throughout the corpus-from the Tractarian papers of the 50 's, through the interest in rule-following and nominalism during the 60 's, the material on sensation and perception in the 70's, and into the process ontology and attention to nonlinguistic cognition in the early 80's. In addition, there are voluminous discussions of picturing in the literature descended from Sellars: Jay Rosenberg in effect wrote two books on the subject, Jim O'Shea and Bill DeVries each devote extended discussions to picturing in their respective books on Sellars, and there are over a dozen other papers on Sellarsian picturing in various publications, along with an extended essay by Jeff Sicha circulating in manuscript form. This material would need to be addressed if exegetical concerns were more to the fore, and doing so would quickly derail the line of thought I aim to lay down.

${ }^{6}$ Rorty quotes this passage at page 141 of PMN and discusses it approvingly in the following pages. One way of reading the remainder of part 1 is as an argument that Rorty himself is committed to a Sellarsian conception of picturing. 
subject to the rights and responsibilities that these arrangements bring with them, is not to be understood as some matter-of-factual change that happens to them on their $18^{\text {th }}$ birthday. Instead, this is a change that occurs because of the person's standing in society. And so to say that someone at 18 years of age is now entitled to own a car is not to describe some ontological shift they have undergone; it is instead to express a recognition that we now will afford them. Similarly, to call someone a knower, by Sellars' lights, is to recognize them in a certain way—in particular, it is to recognize them as in principle capable of participating with us in a conversation where what anyone says has rational force on everyone else. A knower is one whose claims constrain our own, and for whom our own claims are constraints. Given that picturing is supposed to be an isomorphic relation between two real-world domains, our question now becomes: how might an isomorphic relation between a knower and her environment bear on when we are warranted in recognizing her as a knower?

The first thing to note is that although calling someone a knower may be more like recognizing than describing them, it would be too quick to cut the socio-recognitive interpretation of knowledge-ascription free from descriptive commitments entirely. Even if saying that someone knows something is to be understood as recognizing them as standing in the space of reasons, descriptive facts about their place in that space, and their relation to the world about which they are recognized as knowers, bear on whether that recognition is warranted. Comparison with more straightforwardly social statuses can once again illuminate the point. It is not for nothing that we place the age of legal consent at 18 rather than at 5 or 35 . For even if to say of someone that their signature now enables them to own a car is to give expression to a form of recognition rather than to make a claim about an ontological change they have undergone, it is 
just as certain that facts about what is generally true of 18-year-olds bear on why that recognition is warranted at (roughly) that age.

By the linguistic criterion of mental state ascription, being a knower is being a converser, one who can engage with us intelligently. Because of this, attributing a claim of knowledge to someone involves undertaking commitment to the claim that the putative knower would be able to reason publicly about the content of that ascription if called on to do so. This feature of knowledge ascription is reflected in the conditions under which an ascription is retracted. For if A cannot tell us anything about what follows from and is ruled out by $\mathrm{p}$, then A cannot be said to know that p. $^{7}$ Simply uttering $\mathrm{p}$ does not suffice to warrant that the utterer knows that $\mathrm{p}$. When knowledge is construed as a matter of standing in a space of reasons, the capacity to engage with an interlocutor in a conversation about the content of the claim is a necessary condition on warranting an ascription that the speaker knows what she is talking about (notice that this may not be a sufficient condition, and at any rate some hedging on 'capacity' would be need to account for cases of, e.g., sleep and paralysis). A putative knower who cannot articulate her knowledge is not entitled to that recognition, just as a wedding without informed consent is no wedding at all.

Here we have the materials for the mental side of an isomorphism in the real order. The utterance counts as knowledge only if it is situated within a space of inference, and its situation in that space is given by the linguistic dispositions of the putative knower. ${ }^{8}$ The utterer is

\footnotetext{
${ }^{7}$ By the recognitive theory of knowledge ascription, the modal in 'cannot be said to know' here is in the first instance normative, a claim that recognition in such cases is not warranted. Thus, the activity of reasoning gains its metaphysical significance as that activity which is constitutive of thought in virtue of the fact that reasoning is a condition on warranting recognition. This is to say that commitment to a material claim about what a knower is finds its ground in formal claims about when we are entitled to apply the term 'knower.'

${ }^{8}$ Those familiar with Sellars' work on picturing will recognize a tacit appeal here to a guiding theme of "Truth and 'Correspondence,"” a 1962 paper devoted to picturing: "espousal of principles is reflected in uniformities of performance" (216).
} 
warranted recognition as a knower in virtue of the fact that the utterer's dispositions are such as to make her capable of articulating the content of what was uttered should the need arise. These dispositions are powers in the causal order, elements of the real. If this dispositional structure, or some subset of it, could be mapped into a domain of objects, properties, processes, states of affairs, or whatever one's favored ontology, such that we were in possession of a function that permitted our using the dispositions and the ontology in order to read the terrain of the world and the contents of an utterer's mind off of one another, then we would have a defense of picturing, as an isomorphic relation between elements in the real order, from within a normative frame on knowledge ascription.

An inferential understanding of the content of a knowledge ascription will not simply as such invoke picturing relations, however. For all terms stand in inferential relations, and if we identify a disposition to reason with the picturing of objects then platonism is straightaway upon us. But our logic should not settle whether a substantive metaphysical commitment like platonism is true. It is only when we are independently committed to there being referents for the terms of a discourse that the use of those terms will count as picturing. As the home language game of picturing is with world-directed thought, it is to the warranting conditions for ascriptions of perceptual knowledge that we must turn.

The inferential space that a perceptual knower must navigate is a space of nouns and verbs, adjectives, and adverbs; units of identity and the features that identify them. Bracketing semantic and metaphysical concerns, I will speak in terms of an ontology of objects and powers (or properties) and a semantics of singular terms and predicates. The objects and powers we purport to know interact in ways that elicit different responses from other objects, and via this interaction we are afforded determinate contents of knowing. This being so, the capacities to 
reason that justify ascriptions of perceptual knowledge are capacities that include the use of singular terms and predicates in ways that reliably co-vary with the causal interactions among the objects and properties that the use of those terms purport to describe. Embodied in particular in our facility with subjunctive conditionals, this capacity to reason about the space of implication surrounding a given descriptive claim, and thereby to reason about the space of possibility surrounding the objects and powers referred to in that claim, is a capacity that admits of degrees - a participant need not be flawless in her performance, but if she cannot at least tolerably play the game we simply will not be able to understand her as knowing what she seems to be talking about. ${ }^{9}$ Knowledge that some pile of rock is salt or sugar, or that some liquid is water, involves knowledge of such subjunctive conditionals as: if either the salt or the sugar were to be immersed in water it would dissolve, but that the resulting salt solution would conduct electricity while the sugar solution would not. Even if she does not voice these subjunctives, she must be such that were some of these conditions realized she would judge differently so as to represent that change.

In perceptual knowledge, then, the linguistic structure characterized by the use of singular terms and predicates is one whose elements must reliably co-vary with the structure characterized by objects and their powers if the knower is to count as a knower at all. Generalizing out of the object/power restriction, with this we have a function capable of characterizing an isomorphism in the real order between mental events, conceived as linguistic episodes, and the world. This is an isomorphism whose domain is linguistic dispositions and whose co-domain is some suitable ontology. And the function that specifies the mapping between these two domains is whatever language we use to translate the actualizations of these

\footnotetext{
${ }^{9}$ The idea that counterfactual reasoning is a condition on the grasp of ordinary descriptive content is put forth and defended in various ways by Peirce in "Issues of Pragmaticism," Sellars in "Counterfactuals, Dispositions, and the Causal Modalities," and Brandom in chapters 4 and 5 of Between Saying and Doing.
} 
linguistic dispositions--in the simplest case that function is simply the language used by the putative knower. We read the actualizations of these dispositions as pictures of the world precisely because we understand the language being spoken (notice our assessment is internal to a given language). If to be a knower of the world is to be a reasoner about the world, and to be a reasoner about the world is to be disposed to judge differently were various conditions to be realized, then to know the world is to picture it in Sellars' sense. In the material mode, Sellarsian picturing is a condition on the possibility of perceptual knowledge.

That there is, for any perceptual discourse at any stage of inquiry, a function from mental events to some (supposed) ontology is a condition on the possibility of perceptual representation within that discourse; but the function that governs the isomorphism is not something that we imagine to be the same at every stage of the discourse, fixed once and for all. Instead, that function is constantly undergoing revision as we undertake first-order empirical inquiry, whether about ourselves or the world. Linguistic and ontological commitments are constantly being reworked, and so the function that relates them is perpetually changing and always internal to a given language. But because at every stage such a function is a condition on the possibility of perceptual knowledge, and because of the way we revise our view on the basis of rational inquiry, we can see ourselves and our shared history, despite the inevitability of revision, as one community in conversation. Picturing is not meant to get us 'beyond' or 'outside' our current discourse; it's meant as a theoretical postulate to be used from within a discourse so as to help develop it by helping to understand just who we are and what we do. 


\section{Part 2: Analogy and the Lamp of Reason ${ }^{10}$}

The possibility of linguistic revision broached at the end of part 1 raises the prospect that linguistic dispositions are in fact an imperfect expression of a more primitive form of cognitive responsiveness to the world, embodied in the central nervous system, that is more properly the domain of the mental side of picturing's isomorphism. And with a transition to a theory of mind in the scientific image we face the prospect that conventional linguistic categories and commonsense ontology, while offering a first pass at a framework for thinking about how the mind relates to the world, would need to be revised over the course of the inquiry. This revision is, in practice, the construction of a new language more adequate to what we come to believe about ourselves and our place in the world.

The move to self-consciously reshape the contour of linguistic habit by searching for new ways to talk about ourselves bears some resemblance to the sort of thing that Rorty discusses as edification. But Rorty famously contrasted edifying with systematic philosophy, at points simply equating edifying philosophy with an aim to "prevent conversation from degenerating into inquiry, into a research program" (PMN, 372; cf. 367-8). We can give Rorty the term if he'd like, and perhaps he would prefer to see what follows as an instance of systematic revolutionary philosophy without being edifying (cf. PMN 369-70). The more interesting question is whether Rorty's positive characterization of edifying philosophy makes it, as such, a practice incompatible with systematic philosophy. At page 360 Rorty introduces edification as follows:

Since "education" sounds a bit too flat, and Bildung a bit too foreign, I shall use "edification" to stand for this project of finding new, better, more interesting, more fruitful ways of speaking. The attempt to edify (ourselves or others) may consist in

\footnotetext{
${ }^{10}$ In composing part 2 of this paper I have benefitted from conversation with Randy Auxier, and from consultation with his Signs and Symbols: An Analogical Theory of Metaphysical Language, PhD dissertation in philosophy, Emory University.
} 
the hermeneutic activity of making connections between our own culture and some exotic culture or historical period, or between our own discipline and another discipline which seems to pursue incommensurable aims in an incommensurable vocabulary. But it may instead consist in the "poetic" activity of thinking up such new aims, new words, or new disciplines, followed by, so to speak, the inverse of hermeneutics: the attempt to reinterpret our own familiar surroundings in the unfamiliar terms of our new inventions.

In the remainder of this paper I want to show one way in which the role given to edification in the above passage can be made compatible with a systematic philosophical methodology. For it is possible to see oneself as engaged in a project that is at once an expression of the need to get beyond the deficiencies of current modes of thought by critiquing current practice and suggesting alternatives, and yet which aims to make a contribution to the ongoing construction of an adequate epistemology, a theory of humanity's place in the world as agents and knowers. As a way of thinking about such a construction I will focus on inference by analogy, and begin by contrasting it with the process of picturing discussed in part 1 of this paper. ${ }^{11}$ In an analogical inference one adopts the explanatory resources of one domain (commonly called the analogical 'source' or 'base') in order to draw inferences about and so potentially explain the activities of

\footnotetext{
${ }^{11}$ Analogical inference became a growing topic of interest in the $2^{\text {nd }}$ half of the $20^{\text {th }}$ century, first in the philosophy of science and then in artificial intelligence and cognitive science. Work by Mary Hesse $(1953,1966,1966,1974)$ and Paul Bartha (2010) provide points of entry for the former. The anthologies of Helman (1988) and Gentner, Holyoak, and Kokinov (2001) offer overviews with regard to the latter. Bartha (2010) aims to address some of the normative dimensions of analogical inference that are not to the fore in the cognitive science literature on analogical reasoning, where the focus is more commonly on modeling, e.g., child learning. My own inroad to analogical inference comes out of Hegel's Science of Logic, where inference by analogy is associated with the syllogistic figure that Peirce describes as abduction. For a critical discussion of this assimilation of analogy to abduction, see my (forthcoming).
} 
the elements of another domain (the analogical 'target'). ${ }^{12}$ One identifies elements of the source domain that stand in structural relations that are similar to relations among elements of the target domain, and uses an antecedent grasp of the source relations to model features of the target domain. Thus, the model of the solar system might be used to construct a model of the atom. ${ }^{13}$ Elements of the source domain, hallmarks that are salient in our understanding of the relations governing the operations of the source domain, are paired with elements (hallmarks) of the target domain, but the mapping is not primarily aimed at finding attributes (monadic properties) that are had by the hallmarks of the source domain and shared by attributes of the hallmarks of the target domain. Instead, it is characteristic of analogical inference that the mapping from source to target is governed by an interest in preserving structural relations between elements of the source domain, finding analogous relations among the elements of the target domain, and then projecting inferences from the source domain into the target domain. ${ }^{14}$ Thus, one does not need to find properties of the sun and the planets (e.g. mass and composition) that are had also by neuclei and electrons in order to specify an analogy between the solar system and the atom; instead, it is the gravitational relations between the sun and the planets that guide an analogous understanding of the relational structure of the atom. After identifying hallmarks in the source domain whose operations are governed by relations structurally analogous to the relations governing corresponding hallmarks in the target domain, we transpose the categories of the analogical source into the domain of the analogical target, develop a commentary specifying how

\footnotetext{
${ }^{12}$ For a discussion of the stages of analogical reasoning in the cognitive science literature, see Burstein (1988), 17980; Thagard (1988), 107ff; Gentner and Colhoun (2010); and Gentner and Smith (2012), 131-4. For Hesse's account see pages 57-100 of her (1966). Bartha's analysis is given in chapter 4 of his (2010).

${ }^{13}$ Though Bartha, in a footnote at page 4 of his (2010), notes that while this analogy is commonly invoked, it does not seem to have played a role in Ernest Rutherford's development of his model of the atom.

${ }^{14}$ The view that analogical inference is interested in preserving structural relations between elements, rather than the attributes of individual elements, is defended in Gentner (1983), and has since become a standard feature of accounts of analogical reasoning.
} 
to apply the transposition (including where the analogy breaks down-Bartha's 'negative analogies'), and endeavor to read information off of that latter domain with the resources imposed by the transposition. In doing so we reorganize our comprehension of the target domain - the categorial schemata of the source domain, complete with commentary, provide new modes of reasoning about the elements of the target domain. If the analogy is a good one, the use of the categories of the analogical source for understanding the analogical target will bring to light salient features of the target domain that went unnoticed, or will allow us to compress a complex set of data into a more manageable load (as in the use of the categories of intentional agency for interpreting organic activity). In some cases, one goes on to abstract from the structural relations that are shared between source and target domain, constructing a more general account of the processes that are in common between both domains. ${ }^{15}$ The generalizing of a relational structure common to both domains can be thought of as a movement from a fourterm or proportional analogy:

\section{$A: B:: C: D$}

to what Auxier (1992) calls a 'three-term' analogy, where the terms A and C, used to characterize features of B and D relevant to the analogy, are themselves understood in terms of some more general process or operation. So the proportional analogy

neurophysiological processes : human thought :: binary computation : computer processing would, if tenable, impel us to consider whether and in what sense neurophysiological processing and the binary computation of computers might be understood in terms of the operation of some structure of relations general enough to be able to work across both the brain and a computer. Were some more general account available, we would then have a 'three-term' analogy in the

\footnotetext{
${ }^{15}$ On such generalization or abstraction see Burstein (1988) p.180, Gentner and Colhoun (2010) p.42, and Gentner and Smith (2012) p.133.
} 
sense that human thought would be analogous to computer processing in virtue of the fact that both are governed by this more general set of structural relations operative both on the side of neurophysiology and in computer hardware (as it happens, of course, it seems that this proportional analogy does not underwrite an abstraction to the corresponding three-term analogy, as the neurophysiology of the brain is too dissimilar to binary computation; thus the move to parallel distributive processing or connectionist networks).

Analogical inference differs from the functional application employed in constructing a model of picturing in at least two respects. In the first place, picturing is concerned with an isomorphism that preserves both the attributes of the individuals and the relations between them, whereas analogical inference is less concerned with the former and instead focuses on the latter. Second, whereas the function that governs the mapping between the domain and co-domain of a picturing relation is a function between two domains whose elements are already identified and individuated, with an analogical inference we use the categorial resources of a domain we understand so as to interpret a co-domain for which we do not have an adequate understanding. In the functional application that specifies a picturing relation a mirror metaphor is apt: there one sets up an isomorphism mapping elements of one domain onto the other, pairing properties as well as relations, with the domain and co-domain fixed once and for all (in the context of that isomorphism). Inference by analogy is, by contrast, a dynamic process whereby a conception of the analogical target undergoes development by extending a partial use of the analogical source's categories into a new context. The metaphor here is not that of mirroring an antecedently illuminated surface, but of illuminating an uncharted territory. With analogical inference our effort is not one of polishing the mirror of nature but of using the lamp of reason to help us get a better view of our surroundings. 
Analogical reasoning was already in play in the discussion of picturing in part 1 , as we there supposed that the categories of linguistic theorizing could be used as a source from which to construct a theory of mental events more generally (see Hesse 1966, 1974, and Bartha 2010 for a defense of the view that analogical reasoning is central to scientific theorizing). The use of one theory as a model from which to construct another was a common theme in Sellars' efforts to understand persons as part of the natural world. At the core of Sellars' account is the thought that our dispositional capacities for linguistic utterances, as causal responses to the environment, provide a way of naturalistically grounding our norm-laden capacities for rational agency and cognition. Sellars focused on three types of linguistic dispositions: language-entry moves give voice to a perceptual response to the environment (lo, smoke); language-language moves give voice to some bit of reasoning (where there is smoke, there is fire); and language-exit moves give voice to our behavioral proclivities (I shall leave now). These linguistic dispositions were supposed to be the overt public expression of capacities for perceptual takings, the drawing of inferences, and the formation of volitions. The relations among these three sorts of capacities are, of course, analogous to the relations among the three moments of the central nervous system - sensation draws in environmental information, the central nervous system processes that information, and this processing results in motor responses. It was Sellars' belief that by being raised in a linguistic community our evolved nervous dispositions were capable of being more than merely causal responses to the world. Instead, by coming to speak a language our dispositional responsiveness to the environment became a responsiveness to reasons as well. Nevertheless, the actualization of these dispositional capacities, even in their conceptually articulate form, were not actions in the sense in which, e.g., choosing to look into the corner, to 
spend an afternoon pondering a problem, or to act on a volition are properly actions. From "Meaning as Functional Classification" (88):

It is the pattern-governed activities of perception, inference, and volition, themselves essentially non-actions, which underlie and make possible the domain of actions, linguistic and non-linguistic.

While working on this material Sellars developed a theory of rule-following and linguistic training meant to make intelligible how the norm-laden reason-mongering we engage in could come to be in nature. ${ }^{16}$ Central to his account is the distinction between rules of action, conformity to which require that the things they govern be capable of framing a conception of the rule in question so as to act from a recognition of the propriety of the action the rule enjoins, and rules of criticism, conformity to which is a matter of habituated patterns among nonagentive states and behaviors. While the child is at first merely subject to rules of criticism others enforce on her by shaping her dispositions without the child herself reacting as she does on the basis of her conception of those rules or their propriety, the child becomes a full-fledged member of the community when she is able to frame her own rules of action so as to enforce the rules of criticism that govern her (and others) in the community (cf. "Meaning as Functional Classification,” p.86). By grounding rational thought and agency in evolved and educated nonagentive dispositional activities, Sellars hoped to help explain the place of persons in nature. From Naturalism and Ontology (1974, 110):

...the fact that the uniformities (positive and negative) involved in language-entry, intralinguistic and language-departure transitions of a language are governed by specific ought-to-be statements in its meta-linguistic stratum, and these in turn by

\footnotetext{
${ }^{16}$ The central texts are "Some Reflections of Language Games" (1954), chapters 6 and 7 of Science and Metaphysics (1967), "Language as Thought and as Communication" (1969), and "Meaning as Functional Classification" (1974).
} 
ought-to-bes and ought-to-dos concerning explanatory coherence, constitutes the Janus-faced character of languagings as belonging to both the causal order and the order of reasons. This way of looking at conceptual activity transposes into more manageable terms traditional problems concerning the place of intentionality in nature.

I have been presuming that we reason analogically when one domain is supposed to be understood and the other in need of elucidation. But inference by analogy can also proceed by comparing two domains against each other where neither domain is intelligible entirely on its own (Kurtz, Miao, and Gentner 2001; Gentner 2010). ${ }^{17}$ In such a case the categories of each domain are employed in structuring an understanding of the other. Kurtz, Miao, and Gentner call this process 'mutual alignment' and characterize it as follows (Kurtz, Miao, and Gentner, 419): In mutual alignment the learner is simultaneously presented with two analogous situations that act symmetrically in the mapping process: Both can serve as sources and recipients of information. Under these conditions, comparison between two partially understood situations can lead to noticing parallel structure and developing a deeper understanding of both situations.

Additionally, it is possible to take multiple domains as sources for an account of a single target domain (cf. Bartha 2010, 141ff.), or to take one domain as an analogical source and construct a theory of multiple targets (as the evaluative modes of judgment at work in explaining agency are often used in explaining the activities of organisms, institutions, and the behavior of recalcitrant artifacts). Together, these additional degrees of freedom open up the possibility for analogical reasoning to proceed by reciprocally transposing a multitude of categories across different

\footnotetext{
${ }^{17}$ In contrast to the approach that Gentner adopted in her (1983), on which the source analog is already understood and the target analog interpreted thereby, in her (2010, 755-6) she says that an approach where neither analog is independently well interpreted is a more realistic account of how young children in fact learn.
} 
domains (complete with a commentary), none of which domains are wholly understood on their own and so all of which stand to gain by the transposition. With this expanded conception of analogical inference we can begin to think about ways in which our understanding of both the natural and the socio-linguistic processes that shape our dispositional capacities might be informed by one another.

The evolution of such things as we are has been, in large part, an evolution of ever more complex capacities to sense, think, and act. Here we have a set of hallmarks standing out in the domain of evolutionary neurophysiology as points for orienting our understanding of the human being qua natural thing. The relations among these hallmarks are governed by processes of natural selection in the species and habituation over the course of individual lives. But when one turns to the socio-historical changes of the cultures within which we have come to say 'we' to one another, one finds all manner of hallmarks by which to characterize those changes. Those that perhaps most starkly stand out for a transposition of the nervous activities of sensing, thinking, and acting into the frame of historical change are the notions of beauty, truth, and goodness. By analogy with the processes of natural selection and habituation that shape the relations among and development of sensory, central, and motor nervous activities, perhaps there are similar processes of socio-historical change that shape the relations among and development of our concepts of beauty, truth, and goodness. The idea here is that just as human evolution can be understood as the development of ever more complex capacities to sense, think, and act, so might human history be conceived, by analogy, as the development of ever more subtle conceptions of beauty, truth, and goodness. This is an instance of a proportional analogy, and it can be represented as follows:

evolution : sensation, cognition, behavior :: history : beauty, truth, and goodness 
Evolution (a natural process) is to the development of sensory, central, and motor nervous complexity as history (a social process) is to the development of the notions of beauty, truth, and goodness. This proportional analogy leaves the relationship between the evolutionary and historical processes governing the development of these respective domains undecided. For this reason, those who advocate a stage of generalization or abstraction in analogical reasoning (Burstein 1988, Gentner 2010, Gentner and Colhoun 2010, Gentner and Smith 2012) might encourage us to investigate whether a more general account of these processes could be provided, one on which the evolutionary and historical dimensions of development could be seen as two aspects of a more basic process of development. In this we would move from what Auxier calls a 'four term' to a 'three term' analogy.

Of course, the historical development of our concern with the notions of beauty, truth, and goodness does not ex ante lay claim to structuring our understanding of the history of our cultures in the way that the evolution of sensory, central, and motor nervous activity structures our understanding of the evolution of human beings - that is part of the commentary we would need to work up. Toward the development of that commentary, we might adopt Peirce's conception of philosophy as the study of the normative sciences of aesthetics, logic, and ethics. For as normative sciences these disciplines are concerned with proper sensation or immediate affective response (aesthetics), proper inference or cognition (logic), and proper volition or behavior (ethics). This being so, these disciplines seem particularly suited for inquiry into beauty, truth, and goodness as a socio-historical expression of our evolving dispositions to sense, think, and act. We would then be faced with a proportional analogy of the following form: ${ }^{18}$

\footnotetext{
${ }^{18}$ As it relates three domains rather than two, this is no longer a 'four-term' analogy properly so-called. For this reason 'proportional analogy' is more apt.
} 
evolution : sensation, cognition, behavior :: history : beauty, truth, and goodness :: reason : aesthetics, logic, ethics

In order to move to the corresponding three term analogy we would need to show that the natural processes of evolution, the social processes of history, and the rational processes of philosophical inquiry can be profitably interpreted as three specifications of one more general theory of being and becoming.

We now have three domains (nervous system structure, world-historical notions, and philosophy as the study of normative science) each divided into three subdomains whose hallmarks stand in intradomain relations to one another that are potentially structurally analogous to the intradomain relations of the corresponding hallmarks of the other domains. If there were profit to be had in reasoning analogically here, using features of the relational structures of each domain to understand the others, we might flesh out our understanding of ourselves as creatures capable of raising such questions as "what can I know?" "what ought I do?" and "what may I hope?" by thinking about the capacities lying behind these questions as capacities whose actualizations are the result of processes whose operations are the natural, socio-historical, and rational aspects of a more general set of laws or tendencies. ${ }^{19}$ This in turn might offer us new answers to these and other questions, and so new ways of using such capacities. Suppose we take the temporal frames of evolution among species and education among social individuals as alternating foci for plotting this development. Modulo the need for both a rich enough pedagogy and a sufficient grasp of the features of evolution that have, in fact, shaped our modes of activity, I propose that we can just barely make out a view on which the practice of education, in whatever form it manifests itself, is a practice of cultivating philosophy in Peirce's sense, where

\footnotetext{
${ }^{19}$ This is a way of saying that Kant's fourth question, “what is a human being?", is indeed the most fundamental, as he notes in the Jäsche Logic, p.538 (9:25 in the Academy pagination).
} 
philosophy is the birth into self-conscious development of a set of capacities that have been naturally evolving for eons, and which, by its nature as the pedagogical practice it is, results in the emergence of individual persons as rational agents. I believe such a view deserves to be seen as both systematic and edifying. And by tracing its intellectual roots in the service of its further articulation it suggests one way of 'going beyond' Richard Rorty.

For while the Kantian and Hegelian dimensions of this view will be evident, there is another historical strand to this work that seems less well known. Though Sellars does not do much to note this inheritance, it is clear that his account of language-transitions and habituated nervous dispositions is a descendant of classical American pragmatist interests centering on the reflex arc as a guide to understanding human agency and cognition. ${ }^{20}$ These interests themselves flourished in the late $19^{\text {th }}$ century against the background of a protracted engagement in American higher education with European influences. Peirce, James, and Dewey were, like Sellars, convinced that Darwinian modes of explanation would provide new ways of understanding socio-historical change and personal development. ${ }^{21}$ This was a project occupying American philosophers throughout the second half of the 19th century and into the 20th. The first half of the $19^{\text {th }}$ century had sown the seeds for it in the various multi-volume texts on political science, individual psychology, morality, and the sentiments written for upper level university courses of that time, an interest fed by French, German, and Scottish enlightenment influence on American conceptions of political economy and civic duty. There was in the U.S. at this time a cottage industry in such textbooks, and the multi-semester courses that taught them were seen as the capstone to a university education. With the publication of Darwin's On the

\footnotetext{
${ }^{20}$ Classical statements are James' “The Reflex Action and Theism” (1897) and Dewey's “The Reflex Arc Concept in Psychology" (1896).

${ }^{21}$ And Peirce, like Sellars, thinks that the capacity for framing self-directed conceptions about how one's habits ought to be organized is what grounds the transition from rule-conformer to rule-follower, mere human being to person in the community (Peirce 1905, 347; 1906, 278, 284, 286; and 1905b, 296).
} 
Origin of Species these works were reorganized on principles drawn from the new biology, and the second half of the 19th century saw a proliferation of such treatises. In correspondence Darwin himself asked Chauncey Wright, the "Cambridge Socrates" and member, along with James and Peirce, of the Metaphysical Club at Harvard, to apply his (Darwin's) views to the questions of mental life. The result was Wright's "The Evolution of Self-Consciousness," published in The North American Review in 1873 (Schneider 1963, 304). ${ }^{22}$

Immersed as they were in this intellectual climate, Peirce, James, and Dewey each in their own way took up these Darwinian resources and began to frame systematic views about persons that included a central role for evolved and educated dispositions across nervous system structures. Sadly, the thought that a philosophical study of the mind, the moral sentiments, and civic duty would be the capstone of an education, still alive in the time of James and Dewey, has long since faded from practice. But the effort to rethink the natural character of rational thought and agency through a Darwinian frame lived on in the work of Critical Realism and New Realism at the start of the 20th century. With the exception of Wilfrid Sellars' efforts this, too, seems to have passed out of American philosophical interest by the middle of the last century. Those who have been influenced by Sellars often employ resources that descend from this tradition, but in most cases the resources remain only in vestigial form. No longer playing the role they once did, they are instead worked up under different auspices. While connections between Sellars' work and the German Idealists are drawn to the fore by people like Brandom and McDowell, it may be that philosophers working in this area have something to gain by turning to American intellectuals of the $19^{\text {th }}$ century as well. Chauncey Wright's argument that the origin of self-consciousness could be naturalistically explained by showing how primitive faculties would acquire new functions in a social setting sounds like nothing so much as the

\footnotetext{
${ }^{22}$ See chapters 30-33 of that book for an overview of this period of American philosophical development.
} 
technique of "algorithmic elaboration" by which Brandom, in Between Saying and Doing, shows that certain practical capacities suffice to introduce vocabularies that have an expressive power strictly richer than any vocabulary used in those practices. By these lights, one way to go beyond Rorty would be to reclaim a view of philosophical history as philosophical development. I hope to have indicated one line of development in the history of American philosophy that offers some conceptual resources for articulating that view.

\section{Bibliography}

Auxier, Randall. 1992. "Signs and Symbols: An Analogical Theory of Metaphysical Language." $\mathrm{PhD}$ diss., Emory University.

Bartha, Paul. 2010. By Parallel Reasoning: The Construction and Evaluation of Analogical Arguments. New York: Oxford University Press.

Brandom, Robert. 2008. Between Saying and Doing: Towards an Analytic Pragmatism. New York: Oxford University Press.

Burstein, Mark H. 1988. “Combining Analogies in Mental Models,” in Helman 1988, 179-203.

DeVries, Willem A. 2005 Wilfrid Sellars. Ithaca: McGill-Queen's University Press.

Dewey, John. 1896. “The Reflex Arc Concept in Psychology.” In The Philosophy of John Dewey: Two Volumes in One, edited by John J. McDermott, 136-148. Chicago: The University of Chicago Press, 1981.

Gentner, Dedre. 1983. "Structure-Mapping: A Theoretical Framework for Analogy." Cognitive Science 7: 155-170.

--- 2010. "Bootstrapping the Mind: Analogical Processes and Symbol Systems." Cognitive Science 34: 752-775.

Gentner, Dedre and Julie Colhoun. 2010. "Analogical Processes in Human Thinking and Learning." In On Thinking: Vol. 2. Towards a Theory of Thinking, series editors A. von 
Müller \& E. Pöppel, volume editors B. Glatzeder, V. Goel, \& A. von Müller, 35-48. New York: Springer Science.

Gentner, Dedre, Keith J. Holyoak and Boicho N. Kokinov, eds. 2001. The Analogical Mind: Perspectives from Cognitive Science. Cambridge: The MIT Press.

Gentner, Dedre and L. Smith. 2012. “Analogical Reasoning." In Encyclopedia of Human Behavior, $2^{\text {nd }}$ ed., edited by V.S. Ramachandran, 130-136. Oxford: Elsevier.

Helman, David H, ed. 1988 Analogical Reasoning: Perspectives of Artificial Intelligence, Cognitive Science, and Philosophy. Boston: Kluwer Academic Publishers.

Hesse, Mary. 1952. "Operational Definition and Analogy in Physical Theories." The British Journal for the Philosophy of Science, 2 (8): 281-294.

--- 1964. “Analogy and Confirmation Theory.” Philosophy of Science, 31 (4): 319-327.

--- 1966. Models and Analogies in Science. Notre Dame: University of Notre Dame Press.

--- 1974. The Structure of Inference. Berkeley: University of California Press.

James, William. 1897. “The Reflex Action and Theism.” In The Will to Believe and Other Essays in Popular Philosophy, 111-114. New York: Dover Publications, 1956.

Kant, Immanuel. 1992. Lectures on Logic, translated and edited by J. Michael Young. New York: Cambridge University Press.

Kurtz, Kenneth J., Chun-Hui Miao, and Dedre Gentner. 2001. "Leaning by Analogical Bootstrapping." The Journal of the Learning Sciences, 10 (4): 417-446.

O’Shea, James R. 2007. Wilfrid Sellars: Naturalism with a Normative Turn. Malden: Polity Press.

Peirce, Charles Sanders. 1878. "How to Make our Ideas Clear." In The Essential Peirce: Selected Philosophical Writings, Vol. 1 (1867-1893), edited by Nathan Houser and Christian Kloesel, 124-141. Bloomington: Indiana University Press, 1992.

--- 1903. “The Three Normative Sciences.” In The Essential Peirce: Selected Philosophical Writings, Vol. 2 (1893-1913), edited by the Peirce Edition Project, 196207. Bloomington: Indiana University Press, 1998.

--- 1905a. "Issues of Pragmaticism.” In The Essential Peirce, Vol.2, 346-359. 
--- 1905b. “Critical Common-Sensism." In Philosophical Writings of Peirce, edited by Justus Buchler, 290-301. New York: Dover Publications, Inc.

--- 1906. "Pragmatism in Retrospect: A Last Formulation." In Philosophical Writings of Peirce, 269-289.

Rorty, Richard. 1979. Philosophy and the Mirror of Nature. Princeton: Princeton University Press.

Rosenberg, Jay F. 1974. Linguistic Representation. Boston: D. Reidel Publishing Company.

--- (1980). One World and Our Knowledge of It. Dordrecht: D. Reidel Publishing co.

Schneider, Herbert W. 1963. A History of American Philosophy, $2^{\text {nd }}$ ed. New York: Columbia University Press.

Sellars, Wilfrid. 1954. "Some Reflections on Language Games." In In the Space of Reasons: Selected Essays of Wilfrid Sellars, ed. Kevin Scharp and Robert Brandom, 28-56. Cambridge: Harvard University Press, 2007.

--- 1956. Empiricism and the Philosophy of Mind. Cambridge: Harvard University Press, 2003.

--- 1958. "Counterfactuals, Dispositions, and the Causal Modalities." In Minnesota Studies in the Philosophy of Science, Volume II: Concepts, Theories, and the Mind-Body Problem, edited by Herbert Feigl, Michael Scriven, and Grover Maxwell, 225-308. Minneapolis: University of Minnesota Press.

--- 1960. “Being and Being Known.” In In the Space of Reasons, 209-228.

--- 1962. "Truth and 'Correspondence." In Science, Perception, and Reality, by Wilfrid Sellars, 197-224. Atascadero: Ridgeview Publishing Company, 1991.

--- 1967. Science and Metaphysics: Variations on Kantian Themes. Atascadero: Ridgeview Publishing Company, 1992.

--- 1969. "Language as Thought and as Communication." In In the Space of Reasons, 5780.

--- 1974a. "Meaning as Functional Classification: A Perspective on the Relation of Syntax to Semantics." In In the Space of Reasons, 81-100. 
--- 1974b. Naturalism and Ontology: The John Dewey Lectures for 1974. Atascadero: Ridgeview Publishing Company, 1996.

--- 1981a. “The Lever of Archimedes.” In In the Space of Reasons, 229-257.

--- 1981b. “Mental Events.” In In the Space of Reasons, 282-300.

Stovall, Preston. Forthcoming. "Abductive Inference, Autonomy, and the Faith of Abraham." In Interpreting Abraham, edited by Bradley Beach. Minneapolis: Fortress Press.

Thagard, Paul. 1988. "Dimensions of Analogy.” In Helman 1988, 105-124. 